\title{
REQUISITOS PARA VALORAÇÃO DE PATENTES EM UNIVERSIDADES: O CASO DA UNIVERSIDADE FEDERAL DO TOCANTINS
}

\author{
Requirements for patent valuation in universities: the case of the Federal University \\ of Tocantins
}

Requisitos para la valoración de patentes en universidades: el caso de la Universidad Federal de Tocantins

\author{
Francisco Gilson Rebouças Pôrto Junior ${ }^{1}$, Mauricio Santana Ribeiro ${ }^{2}$, Wandson Mendes \\ Pessoa $^{3}$ \\ ${ }^{1}$ Doutor em Comunicação e cultura contemporânea e professor dos Programas de Pós-Graduação \\ PROFNIT/PPGCom/UFT. \\ ${ }^{2}$ Mestre em Propriedade Intelectual e Transferência de Tecnologia para Inovação (PROFNIT-UFT). \\ ${ }^{3}$ Mestre em Propriedade Intelectual e Transferência de Tecnologia para Inovação (PROFNIT-UFT).
}

*Correspondência: Universidade Federal do Tocantins. Programa de Pós-Graduação em Propriedade Intelectual e Transferência de Tecnologia para a Inovação / Núcleo de Pesquisa e Extensão Observatório de Pesquisas Aplicadas ao Jornalismo e ao Ensino (OPAJE-UFT) Av. NS 15, 109 Norte, Palmas, Tocantins, Brasil. CEP:77.010090. E-mail: gilsonportouft@gmail.com.

Artigo recebido em 07/08/2020 aprovado em 10/11/2020 publicado em 17/03/2021.

\section{RESUMO}

A valoração de patentes consiste de uma técnica para estabelecer o preço de venda de uma nova tecnologia, como é o caso das patentes. Este artigo discute como as tecnologias desenvolvidas nas universidades podem ter estabelecido um preço justo de venda, mais especificamente a universidade federal do Tocantins. O estudo mostrou que o número de patentes já depositadas pela universidade foi considerável nos últimos 5 anos, elevando o número de depósitos no INPI e qualificando o estado do Tocantins neste quesito, porém, a discussão centra-se em elaborar um conceito que possa valorar de maneira mais justa a tecnologia e auxiliar quando o processo de transferência de tecnologia for executado.

Palavras-chave: valoração, patentes, transferência de tecnologia.

\section{ABSTRACT}

The valuation of patents consists of a technique to establish the sale price of a new technology, as is the case of patents. This article discusses how technologies developed in universities may have established a fair sale price, more specifically the Federal University of Tocantins. The study showed that the number of patents already deposited by the university was considerable in the last 5 years, increasing the number of deposits in the INPI and qualifying the state of Tocantins in this respect, but the discussion focuses on elaborating a concept that can value technology and assist when the technology transfer process is executed.

Keywords: valuation, patents, technology transfer.

\section{RESUMEN}

La valoración de patentes consiste en una técnica para establecer el precio de venta de una nueva tecnología, como es el caso de las patentes. Este artículo analiza cómo las tecnologías desarrolladas en las universidades pueden haber establecido un precio de venta justo, más específicamente la universidad federal de Tocantins. El estudio mostró que el número de patentes ya depositadas por la universidad fue considerable en los últimos 5 años, aumentando el número de depósitos en el INPI y calificando el estado de Tocantins a este respecto, sin embargo, la discusión se centra en desarrollar un concepto que pueda tecnología más justa y asistencia cuando se realiza el proceso de transferencia de tecnología.

Descriptores: valoración, patentes, transferencia tecnológica. 


\section{INTRODUÇÃO}

Os direitos de propriedade intelectual podem ser altamente valiosos e desempenhar um papel fundamental em muitos campos de negócios. O processo de valoração destes direitos remete para caracterização e ativos (tangíveis e intangíveis) que impactam neste processo. Exemplos como a tecnologia inovadora, os requisitos para transferência de tecnologia o know how sobre a tecnologia e sua aplicação à sociedade são alguns dos exemplos que pode gerar um valor comercial para qualquer propriedade intelectual.

Este artigo, conceitua os requisitos discutidos na literatura para valorar a propriedade intelectual (PI), como requisito necessário para venda e possível transferência dessa tecnologia, a especificar, as patentes. As patentes são conceituadas pelo Instituto Nacional de Propriedade Intelectual (INPI), como: "Um título de propriedade temporária, fornecido pelo governo, que comprova aos proprietários e inventores os seus direitos sobre o produto ou processo". (INPI, 2018).

As patentes no Brasil, de acordo com dados fornecidos pelo INPI, têm como principais depositantes, as universidades federais, que são 09 entre 10 principais depositantes. Esses dados, remetem para a problemática desenvolvida neste artigo, que se baseia em entender como valorar as patentes geradas $\mathrm{e}$ depositadas nas Universidades Federais e quais as variáveis para a transferência de tecnologia destas patentes.

As patentes estão diretamente ligadas a capacidade de Pesquisa e Desenvolvimentos (P\&D), bem como seu desenvolvimento está diretamente ligado a capacidade inovativa e inventiva. No Brasil, os ativos patrimoniais (tangíveis e intangíveis) eram descritos pela Lei 6.404/76, porém a Lei 11638/07 modificou essa classificação objetivando estabelecer normas cabíveis, ligadas às ciências contábeis brasileiras, alinhado com normas internacionais. Os ativos, são a principal base para determinar um valor ligado a produtos, serviços e tecnologias, principalmente quanto aos ativos intangíveis (knowhow) (ADRIANO \& ANTUNES, 2017).

A estrutura para determinar o grau de intangibilidade, é diferenciada pelo processo de criação, pesquisa, desenvolvimento e inovação, em associação às despesas necessárias para determinar o processo de valoração, principalmente quanto a classificação destes ativos e sua importância no contexto da tecnologia. É de ciência que estes conceitos ainda são pouco desenvolvidos no Brasil, principalmente quanto a mensurar o valor de uma propriedade intelectual (PI), iniciado a partir do processo de $\mathrm{P} \& \mathrm{D}$ e sua evolução.

Os objetivos deste artigo são analisar quais as características de valoração de patentes com os objetivos específicos de: a) Identificar quais as características para valoração; b) Como valorar as patentes das universidades federais e c) Como esse processo de valoração contribui para a transferência de tecnologia destas patentes para o mercado.

\section{Valoração de patentes}

Patente de acordo com o INPI (2018) é um título de propriedade temporária, fornecido pelo governo, que comprova aos proprietários e inventores os seus direitos sobre o produto ou processo. Durante a validade da patente, a produção, o uso, a venda ou qualquer exploração da invenção só poderá ocorrer com autorização dos proprietários.

\section{A Organization for Economic Co-Operation} and Development (OCDE) considera que os dados de patentes podem mostrar alterações na estrutura e no desenvolvimento de atividades criativas de um país na indústria, nas empresas e tecnologias. As patentes também podem indicar as mudanças de dependência de determinadas tecnologias, além de sua 
disseminação e penetração científica, técnica e, em última instância, mercadológica. As patentes podem ser utilizadas como fonte de informação para diversas finalidades, dentre as quais se destacam:

(1) identificação de desenvolvimentos tecnológicos;

(2) identificação de alternativas tecnológicas;

(3) identificação de tecnologias emergentes, de modo a caracterizar as tendências do desenvolvimento tecnológico de determinada área do conhecimento;

(4) avaliação de mercados futuros, uma vez que o patenteamento costuma preceder a comercialização em alguns anos;

(5) avaliação das atividades de Pesquisa e Desenvolvimento (P\&D) e detecção de mudanças estratégicas de instituições e empresas. (GUIMARÃES, 2013).

Segundo o Manual de Estatísticas de Patente da OCDE (2009), o valor da patente para o agente privado diz respeito ao fluxo de caixa esperado por ele devido ao controle da patente. Já para a sociedade, o valor da patente (ou do sistema de patentes) reside na abertura do conhecimento associado à invenção, permitindo que outros inventores realizem melhorias sobre aquilo que já feito. Nesta visão, a contribuição da patente para o avanço científico e tecnológico é uma externalidade do investimento privado em proteção para sua tecnologia (PITA, 2010).

A transferência de tecnologias universitárias envolve a inter-relação entre as universidades e outras entidades, como empresas. Quando a transferência se dá por meio de patente geralmente gera-se royalties ou a concessão da tecnologia. Portanto, a transferência traz consigo a necessidade de se ter noção do valor da tecnologia transferida. Alguns autores já vêm argumentando sobre os mecanismos de valoração de tecnologias. Os métodos mais utilizados, segundo Santos e Santiago (2008), para chegar-se a um valor da tecnologia para uma possível transferência são apontados a seguir na tabela 1 . Geralmente, é gerado o pagamento único para utilização de determinada patente:

As metodologias para valoração de tecnologias são: Valoração Baseada no Custo de Desenvolvimento, Valoração por Meio de Múltiplos, Valoração Baseada no Fluxo de Caixa Descontado e a Teoria das Opções Reais. Muitas destas metodologias são amplamente utilizadas em estudos de viabilidade econômica de projetos, como o método de Fluxo de Caixa Descontado. (SANTOS \& SANTIAGO, 2008)

Pita (2010), conceitua que para se calcular o valor de uma patente, segue-se o seguinte caminho para o processo de valoração: “... o valor da patente será o preço de venda ou de compra deste ativo intangível, determinado com base nas suas características técnicas, econômicas e legais".

$\mathrm{Na}$ visão de Santos e Santiago, a tabela 1 foi desenvolvida para conceituar o que cada método fundamenta existente na visão dos autores fundamenta:

Tabela 1. Métodos para valoração.

\begin{tabular}{|c|c|}
\hline $\begin{array}{c}\text { Valoração Baseada nos } \\
\text { Custos de } \\
\text { Desenvolvimento }\end{array}$ & $\begin{array}{l}\text { Este método é uma função } \\
\text { dos custos decorridos do } \\
\text { desenvolvimento da } \\
\text { tecnologia, ou seja, o que } \\
\text { já foi gasto com as } \\
\text { renovações de patentes, os } \\
\text { custos decorridos do uso } \\
\text { de matérias para o } \\
\text { desenvolvimento } \\
\text { tecnologia, entre outros } \\
\text { fatores deste tipo. Para isto } \\
\text { é necessário um } \\
\text { acompanhamento } \\
\text { custos dos } \\
\text { desenvolvimento. }\end{array}$ \\
\hline $\begin{array}{c}\text { Valoração Por Meio de } \\
\text { Múltiplos }\end{array}$ & $\begin{array}{l}\text { Este tipo de valoração } \\
\text { consiste em comparar } \\
\text { valores de } \\
\text { semelhantes, ativos } \\
\text { considera que os ativos } \\
\text { têm pois, } \\
\begin{array}{l}\text { comerciais parecidos no } \\
\text { mercado }\end{array}\end{array}$ \\
\hline
\end{tabular}




\begin{tabular}{|c|l|}
\hline Valoração Baseada no & $\begin{array}{l}\text { É o método mais utilizado } \\
\text { para valorar tecnologias e } \\
\text { tem a característica de ser } \\
\text { simples e objetivo. Esta } \\
\text { metodologia leva em conta } \\
\text { os gaixa } \\
\text { descontando as receitas e } \\
\text { custos }\end{array}$ \\
\hline Valoração por Meio da & $\begin{array}{l}\text { A lógica por trás desta } \\
\text { abordagem é o fato de que } \\
\text { o individuo que possui } \\
\text { uma opção não tem a } \\
\text { obrigação de executá-la, e } \\
\text { sim uma opção de exercê- } \\
\text { la. Portanto, se o valor } \\
\text { esperado pelo individuo no } \\
\text { ato de exercer a opção for } \\
\text { positivo ele executa, do } \\
\text { contrário ele não executa e } \\
\text { a perda é igual ao valor do } \\
\text { investimento na opção até } \\
\text { o momento }\end{array}$ \\
\hline
\end{tabular}

Fonte: Santos e Santiago (2008), Pita (2010), Serra, Martelanc, Sousa (2012).

\section{Requisitos para valoração de patentes}

Por conceito, a valoração é um processo contábil para cálculo e dimensão de um produto, marca, empresa, patentes, propriedade intelectual, etc, que se fundamenta e elementos diretos e indiretos, inseridos no desenvolvimento, contextualização e concepção de valor sobre todas as variáveis que fundamental um ativo (tangível e/ou intangível) (ADRIANO, ANTUNES, 2016).

A valoração de patentes, possui alguns dilemas que precisam ser observados antes de sua elaboração financeira (PITKETHLY, 1997):

a) Para ser patenteável, precisa ser uma invenção única;

b) O princípio da novidade é essencial;

c) $\mathrm{O}$ valor deve assemelhar a valores de concorrentes conhecidos no mercado;

d) As características intrínsecas e extrínsecas devem especificar a patente;

e) Os ativos (tangíveis e intangíveis) devem ser expostos ao determinar esse valor;

Contabilmente, patentes são vistas como ativos intangíveis e recebem tratamento especial no balanço empresarial, conforme destacam Braga e Almeida (2008):

\begin{abstract}
Em linha com a harmonização das normas contábeis internacionais, a Lei $\mathrm{n}^{\circ} 11.638 / 07$ estabeleceu o grupo de contas de intangíveis, classificado entre o imobilizado e o diferido no balanço patrimonial, e que tem como finalidade contemplar direitos que tenham como objeto bens incorpóreos destinados à manutenção da companhia ou exercidos com essa finalidade, inclusive o fundo de comércio adquirido.
\end{abstract}

Neste sentido, é possível afirmar que as patentes constituem "bens incorpóreos" gerando benefícios futuros para seu detentor, porém, quanto à avaliação para valoração, Braga \& Almeida (2008), mencionam unicamente o levantamento dos custos associados ao ativo como método para constituir o valor e reforçam, a importância da existência de um benefício futuro associado, discutindo o desafio gerado neste problema, a ausência de diretrizes para ativos de Propriedade Industrial (PI).

Ao negociar o envolvimento de ativos de PI, o sigilo (uma das obrigatoriedades para depósito e concessão de direito), a dificuldade em observar dos preços praticados como ocorre em mercados organizados, é um desafio considerável, somando-se a isso, inclusive, a falta de regularidade nas negociações, principalmente, sobre ativos intangíveis semelhantes, gerando inviabilidade as tentativas em comparar as negociações conhecidas, com alguma espécie de histórico de negociações passadas.

O processo de valoração consiste em avaliar, de maneira comercial, quanto vale uma patente desenvolvida e depositada em órgãos responsáveis. No caso do Brasil, as patentes são depositadas no Instituto Nacional de Propriedade Intelectual (INPI). Porém, apesar de uma patente ser o princípio de uma nova técnica, novo produto, etc. enfim, algo a ser oferecido ao mercado para satisfazer uma satisfação, um desejo, 
uma necessidade comercial. (KOTLER \& KELLER, 2014).

Historicamente, o primeiro teórico a determinar o dilema sobre a valoração de uma patente, remete para Knight (1964), que distinguiu alguns fatores que interferem em um processo de valoração: o risco e a incerteza. Para o autor, existem duas maneiras de avaliar essas questões: Calcular o grau de risco e incerteza e levantar a expertise necessária através dos resultados da experiência como melhores formas de auxiliar e ao mesmo tempo, julgar de maneira adequada como valorar uma patente, tendo a possibilidade de dimensionar os riscos existentes e forças ou oportunidades inseridas no know-how.

Para elaborar uma precificação quanto ao preço de venda de uma patente, vários autores possuem características diferentes, o que oferece melhor atenção e discussão sobre os requisitos discutidos pela literatura para valorar uma patente:

Para Bienias e Cornelius (2019) existem algumas razões para avaliar uma patente, a partir do pressuposto tecnológico que são divididos em seis categorias:

1. Precificação e estruturação de transações para a venda ou licença (preço de transferência) de tecnologia proprietária.

2 Financiamento de securitização e colateralização para financiamento baseado em fluxo de caixa e financiamento baseado em ativos.

3. Planejamento tributário e conformidade com relação a amortização, abandono, contribuições beneficentes, presentes, preços de transferência entre companhias, estimativa de impostos sobre ganhos embutidos e outras questões tributárias federais.

4. Informações e planejamento da administração, incluindo aprimoramento do valor comercial, planejamento patrimonial e outras questões estratégicas de longo alcance.
5. Análise de falências e reorganizações, incluindo o valor do patrimônio em falência, financiamento do devedor em posse, refinanciamento tradicional, reestruturação e avaliação do impacto do valor da tecnologia nos planos de reorganização propostos.

6. Suporte a litígios e resolução de disputas, incluindo violação, fraude, responsabilidade do credor, controvérsias relacionadas a impostos, violação de questões contratuais, e uma ampla gama de razões relacionadas à privação.

Evidentemente, nem todos os atributos para avaliar, é aplicável a todas as tecnologias, e, cada um desses atributos não tem uma influência igual sobre o valor econômico de uma tecnologia. Alguns são mais importantes em alguns setores do que em outros - e são mais importantes para certos produtos e serviços do que outros. Vale a pena notar também que há uma variação substancial (qualitativa e quantitativa) de influências positivas para negativas para cada atributo.

Analistas, tentam aplicar os métodos de abordagem de mercado (às vezes chamados de comparação de vendas) primeiro no processo de avaliação porque "o mercado" - o ambiente econômico em que ocorrem transações entre partes independentes - é tipicamente o melhor indicador do valor de uma tecnologia. Os analistas pesquisarão "o mercado" para transações de venda e licenças (aluguel) que podem ser úteis na análise da tecnologia, sendo este, um processo sistemático para aplicar o método de abordagem de mercado à avaliação de tecnologia (LIMA, 2013).

\section{Valoração e avaliação de ativos intangíveis}

Ao desenvolver um estudo para identificar a criação de valor e/ou geração financeira é um dos princípios para valorar e avaliar um ativo intangível. Os conceitos contábeis, são os principais métodos para identificar fatores que possam estabelecer o preço de 
uma tecnologia, incorporado pelo know how de qualquer criação no âmbito humano, determinando conceitos como:
a) Valor Econômico Adicional (EVA);
b) Ponto de Equilíbrio e solidez;
c) Ativos e custos inseridos;
d) Técnicas, métodos e processo inovador;

Também se insere neste conceito, a aplicabilidade comercial e a possibilidade de transferência de tecnologia sobre este ativo intangível, principalmente, analisando mercadologicamente, o que já é uma demanda de mercado para as patentes desenvolvidas no campo científico. Esta demanda, fortalece a discussão sobre o valor de uma tecnologia e que tipos de tecnologia se inserem neste contexto. (PADOVEZE, 1999).

Com a redução de gastos no ensino superior por parte do governo federal, é evidente que as universidades não podem utilizar qualquer conceito de tecnologia sem analisar o âmbito de transferência dessa tecnologia para o depósito, pois, sendo já uma demanda nacional, onerar a universidade com uma tecnologia que não tenha aplicação ou benefício mercadológico, industrial e social, é uma realidade e dever dos responsáveis por essas tecnologias.

Utilizando a terminologia para valorar ativos intangíveis, Andriessen (2004), afirma que há duas correntes que consideram a avaliação em termos monetários e não monetários. Neste sentido, o estabelecimento de um valor financeiro, quando utilizando um critério especificamente monetário, precisa conter três tipos de valor, quando, evidentemente, o critério for monetário:

a) Medir o valor, com base em critérios passíveis de observação (tangível);

b) Avaliar o valor, com base nos critérios pessoais;

c) Medir, o processo de inovação e aplicabilidade para transferência de tecnologia para determinar o valor;

Não é razoável e nem simples desenvolver ou determinar o valor ligado a um processo de P\&D ligado a uma patente, porém, os parâmetros para determinar esse valor, principalmente no âmbito da intangibilidade, discute-se, a partir de alguns teóricos da área, pressupostos que podem determinar o valor de uma patente (ADRIANO \& ANTUNES, 2017).

Tabela 2. Teorias e métodos de valoração.

\begin{tabular}{|c|c|c|}
\hline Método & Abordagem & Autor \\
\hline Cálculo do valor de Intangibilidade & Receita & A. T. Stewart (2001) \\
\hline Valor Econômico Adicionado & Mercado & B. G. Stewart (1994) \\
\hline Determinante de Intangibilidade & Receita & Gu e Lev (2011) \\
\hline Fator de Valoração & Mercado & Stanfield (2001) \\
\hline Opção de Abordagem & Receita & Dixit e Pindyck (1998) \\
\hline Fator Tecnológico & Receita & Khoury (1998) \\
\hline Abordagem de Valoração & Custo & Lee (1996) \\
\hline Abordagem de Valoração & Mercado & Reilly e Roberts (1999) \\
\hline Abordagem de Valoração & Receita & Smith e Parr (1994) \\
\hline $\begin{array}{l}\text { Adicional de Coeficiente de Valoração } \\
\text { Intelectual }\end{array}$ & Custo e Receita & Pulic (2003) \\
\hline
\end{tabular}


As teorias sobre valoração possuíram vários autores com teorias que fundamentam o processo de valoração, como princípio utilizado hoje para calcular o valor de um ativo intangível, caso em que se inserem as patentes. Para descrever passo a passo como está citado na tabela 2, descreve-se:

Stewart (2001) afirmava que desenvolver a teoria onde $\mathrm{o}$ ativo intangível gera vantagens competitivas, e como consequência disto, tornaram-se importantes, visto que, é um meio das empresas se diferenciarem dos seus competidores.

Para Stewart (1994) os custos, quando medidos de forma adequada, incluem o retorno normal sobre os investimentos, e que os lucros não começam até que as empresas tenham coberto aquele retorno normal, com a ideia do lucro residual, fundamento da teoria do valor econômico adicionado.

Para Gu \& Lev (2011), os ativos intangíveis ultrapassam os ativos tangíveis em muitas empresas, tanto em valor quanto em contribuição para o crescimento, mas frequentemente são reconhecidos como despesas nos relatórios financeiros e, portanto, permanecem ausentes dos balanços das empresas.

Para Stanfield (2001), fundamentado nos ativos intangíveis, com o conceito de know how para valorar esse processo. Dixit e Pindyck (1998) trouxeram a teoria da opção de abordagem onde a decisão sobre investir exerce e encerra a opção de investimento, desistindo da possibilidade de aguardar novas informações que poderiam influenciar seu desejo de investir, ou determinar o momento mais adequado para realizá-lo.

Para Khoury (1998) o fator tecnológico tornase determinante, principalmente pelo processo de inovação estar diretamente ligado a P\&D. Lee (1996), Reilly e Roberts (1999) e Smith e Parr (1994) desenvolveram a teoria da abordagem de valoração, mas com conotações diferentes, para Lee (1996) a principal finalidade para essa abordagem é o custo aplicado a tecnologia, sendo o custo o pressuposto para valoração.

Para Reilly e Roberts (1999) a teoria se volta para o mercado, onde as condições mercadológicas fundamentam o processo de valoração, e Smith e Parr (1994) o pressuposto é a receita, ou seja, que retorno a tecnologia podem gerar, daí o cálculo de valoração se fundamenta nos ganhos especificamente.

Por fim, Pulic (2003), fundamenta sua teoria no coeficiente intelectual inserido na tecnologia, ou seja, quando maior o processo de inovação e principalmente de aplicação comercial, melhor o processo de valoração desta tecnologia.

Conforme destaca a Organização para Cooperação e Desenvolvimento Econômico (OCDE), o processo para determinar o valor de uma patente, reflete o processo de diferença entre o valor ligado a invenção com e sem proteção e sua aplicação mercadológica. Pitkenthly (1997), afirma que a utilização inadequada do termo patente (em todo tipo de tecnologia), influencia negativamente a identificação de sua eficiência bem como, o valor que vale esta patente, junto com a dificuldade de comparar os ativos presentes na patente e o processo de negociação envolvendo os ativos de propriedade intelectual.

Determinar o valor de uma tecnologia, não é valorar uma patente, pois, a patente está ligada a capacidade inovativa e inventiva, bem como seu processo de transferência de tecnologia. A opção para alguns casos, conforme descreve Gu e Lev (2011), é a não proteção. Nestes casos, haverá um efeito empresamercado, onde a exploração será mais rápida, porém, um ponto negativo é a facilidade de acesso da concorrência e o domínio público sobre esta tecnologia. $\mathrm{O}$ valor resultante será diluído, tanto pela 
massificação, quanto pelo processo de comoditização da tecnologia.

A proteção a uma patente, quanto somente explorado pelo seu depositante ou criador, elimina a concorrência, e dependendo da capacidade de aplicação comercial (transferência de tecnologia), poderá ter um processo de valoração será bem maior, embora, sua massificação comercial (entrada e sustentação de mercado), podem ser lentos e demorados.

\section{Patentes em universidades brasileiras}

As universidades, no Brasil, são as principais desenvolvedoras de pesquisa, essa perspectiva se concentra principalmente quando se fala de patentes. As patentes são intimamente ligadas a inovação. A inovação presume a criação de novidade, criação no âmbito intelectual bem como são alvo das empresas neste aspecto. O INPI, o órgão governamental responsável pela concessão de patentes no Brasil, tem atuado fortemente para que os dados de depósito possam avançar no aspecto de disseminação de informação a fim de que os residentes no país, cada vez mais proteja suas criações.

As universidades brasileiras são as principais depositantes de patentes no Instituto Nacional de Propriedade Intelectual (INPI), conforme mostra a imagem a seguir:

A partir da imagem 1, é possível construir uma lógica de porque o processo de valoração de patentes dentro das universidades do Brasil é tão importante, pois, o número de patentes depositados é significativo e mostra uma realidade de como é imprescindível valorar, para que, quando ocorrer o processo de transferência de tecnologia, essas patentes sejam vendidas por valores justos.

Há um questionamento que são sujeitos a análise constante: "por que valorar patentes nas universidades?" esse questionamento se torna notório, quando parte-se para o pressuposto da dificuldade das universidades em efetuar o processo de transferência de tecnologia, porém, por serem criações passíveis de registro, a medida tomada é a de depositar o pedido e aguardar legislação que permita o processo de transferência de tecnologia dessas patentes.

Imagem 1. Maiores depositantes de patentes no Brasil em 2017.

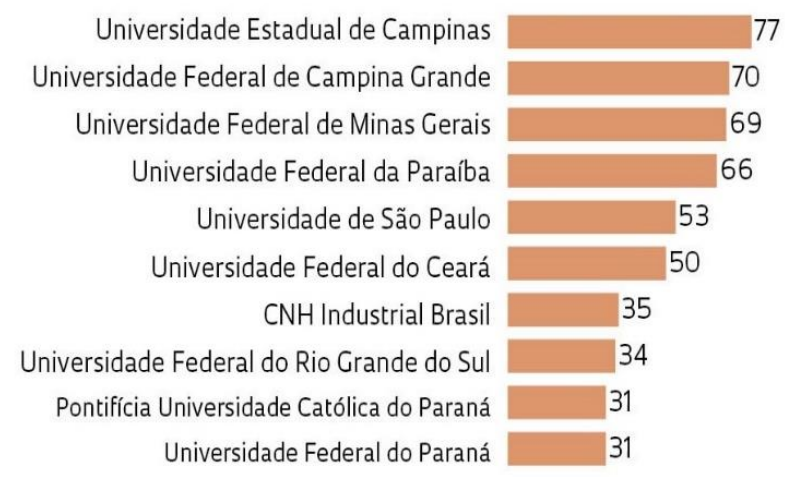

Fonte: INPI, 2018.

Uma das pressuposições que fundamentam a valoração é a análise dos ativos intangíveis:

São todos os ativos que não são físicos ou objetos financeiros. Alguns exemplos são as marcas, a propriedade intelectual, know-how ou segredos de negócio. No contexto atual, de negócios baseados no conhecimento, esses ativos têm papel fundamental para empresas e instituições, uma vez que podem gerar riqueza ao ultrapassar o nível de ganho econômico e financeiro em relação aos negócios baseados na força da mão de obra, na venda de commodities ou em outras formas de trabalho não baseadas no conhecimento (WIEDERHOLD et al., 2009).

A análise dos ativos intangíveis é composta por elementos que estão aquém do plausível, ou seja, dos ativos palpáveis, os ativos intangíveis obtém como conotação, os valores expressos diante das atividades desenvolvidas pela organização, que influenciam indiretamente no objeto final. No caso das patentes, os principais ativos intangíveis são: As horas de estudo para desenvolvimento da patente, o know how, o nível de desenvolvimento e engajamento da universidade no país, o nível de qualificação dos pesquisadores, a 
percepção mercadológica quanto aos objetos desenvolvidos e como as patentes podem ser disseminados pela sociedade. (GUIMARÃES, 2013).

\section{Universidade Federal do Tocantins}

A universidade federal do Tocantins, possui atualmente 07 campus no Estado do Tocantins, com 40 cursos de graduação, 28 de especialização, 32 programas de mestrado e 8 programas de doutorado. A UFT foi fundada em 2000 e implantada no ano de 2003 (UFT, 2019).

A universidade atualmente conta com 345 mestres e 641 doutores. Dentre a comunidade acadêmica, a universidade possui aproximadamente 16.530 alunos que frequentam todas as modalidades entre, graduação, mestrado e doutorado. Atualmente, a Universidade Federal do Tocantins possui 29 patentes depositadas e 3 aguardando o depósito totalizando 32. Esse dado é relevante para evoluir a teoria de progresso do número de depósitos referente ao Estado do Tocantins no INPI até 2017 totalizam 93 patentes depositadas. Destas patentes depositadas pelo Estado do Tocantins, 29 vinte e nove (INPI, 2017) foram depositadas pela UFT, representando aproximadamente $31,18 \%$ do número de patentes depositadas.

Analisando historicamente, o início dos depósitos pela universidade, iniciou apenas no ano de 2013, conforme dados do INPI (2017), verificando a magnitude do papel da universidade no desenvolvimento de propriedade intelectual, fortalecendo a necessidade de participação dos colaboradores das universidades no processo propriedade intelectual.

Analisando os dados da Universidade, desde o número de docentes com qualificação (mestrado e doutorado), bem como cursos de pós-graduação, é possível afirmar que, a produção intelectual, embora ainda bem pequeno em número de produção (o que poderia ser maior se todos se empenhassem nesse princípio), tendem a aumentar significativamente nos próximos anos, com o aumento de ações que incentivem a criação e proteção de propriedade intelectual.

\section{DISCUSSÃO E RESULTADOS}

O processo de valorar uma patente, conforme descrito no texto, passa pelo princípio de utilização de métodos que fortaleçam um preço justo para esta tecnologia. A concepção de Preço justo consiste de um valor onde tanto o comprador quanto o proprietário da patente saiam satisfeitos do acordo estabelecido.

Ao analisar dados sobre as patentes depositadas pela UFT, e a partir desses dados, será determinado que tipo de método sobre como valorar essas patentes para uma possível venda ou aplicação comercial. 


\section{Patentes depositadas pela UFT}

Tabela 3. Relação de Patentes Depositadas entre 2012 e 2018.

\begin{tabular}{|c|c|}
\hline Patente & Descrição \\
\hline $\begin{array}{l}\text { Biofilme de glicerol e seu } \\
\text { uso como agente redutor } \\
\text { da produção de } \\
\text { micotoxinas em produtos } \\
\text { de origem vegetal }\end{array}$ & $\begin{array}{l}\text { A presente invenção descreve a utilização de soluções de glicerol para revestimento comestível } \\
\text { de alimentos, preferencialmente grãos, por imersão, aspersão ou drageamento, para a proteção } \\
\text { contra a produção de toxinas por microrganismos, particularmente fungos. Os biofilmes de } \\
\text { glicerol, além de aumentarem o tempo de prateleira do produto, reduzem a contaminação por } \\
\text { micotoxinas e o risco de intoxicação alimentar. }\end{array}$ \\
\hline $\begin{array}{l}\text { Método de síntese de } \\
\text { criolita a partir de lodo } \\
\text { de estações de } \\
\text { tratamento de água }\end{array}$ & $\begin{array}{l}\text { A presente invenção descreve um método de síntese de hexafluoraluminato de sódio (criolita) } \\
\text { a partir de lodo de estações de tratamento e de outros rejeitos aquosos ricos em alumínio. O } \\
\text { processo envolve um tratamento térmico seguido de tratamento ácido para extração do alumínio } \\
\text { da amostra seguido por um tratamento básico para isolamento do alumínio como íon complexo } \\
\text { e precipitação do alumínio como criolita com tratamento com ácido fluorídrico. O método } \\
\text { apresenta a vantagem de ser um método simples e dar uma destinação econômica ao rejeito das } \\
\text { Estações de Tratamento de Águas. }\end{array}$ \\
\hline $\begin{array}{l}\text { Processo para obtenção e } \\
\text { utilização de pectina, } \\
\text { com alto grau de } \\
\text { metoxilação, de } \\
\text { pericarpo do fruto de } \\
\text { pequi }\end{array}$ & $\begin{array}{l}\text { A invenção compreende um processo para produção de pedtina com alto grau de metoxilação } \\
\text { extraída de pericarpo do fruto de Pequi (Caryocar brasiliense Cambess) com capacidade } \\
\text { espessante. Especificamente, a pectina é extraída utilizando-se água como agente extrator, } \\
\text { concentração menor de } 100 \mathrm{~g} / \mathrm{L} \text {, em temperaturas entre } 15-90^{\circ} \mathrm{C} \text {, por } 1-20 \mathrm{~h} \text {, seguidas de } \\
\text { precipitação e lavagens sucessivas com solvente orgânico, preferencialmente um álcool. A } \\
\text { pectina consiste essencialmente de uma homogalacturonana } \alpha-(1 \rightarrow 4) \text { ligada, com grau de } \\
\text { metoxilação entre } 55-100 \% \text {, grau de acetilação entre } 0,1-10 \% \text {. A pectina é, ainda, caracterizada } \\
\text { por ser um agente espessante em composições farmacêuticas, cosméticas, alimentícias e } \\
\text { químicas, podendo ser utilizada em associação à sais e sacarose. }\end{array}$ \\
\hline $\begin{array}{l}\text { Processo de obtenção de } \\
\text { emulsões de glicerina } \\
\text { para aplicação de } \\
\text { herbicidas }\end{array}$ & $\begin{array}{l}\text { O processo de obtenção de emulsões de glicerina para aplicação de herbicidas demonstra que a } \\
\text { obtenção de emulsões estáveis utilizando a glicerina bruta tratada com ácido fosfórico e seus } \\
\text { respectivos ácidos graxos, permite a elaboração de um produto com características promissoras } \\
\text { para o emprego na aplicação de herbicidas em campo, em substituição ao óleo diesel, uma vez } \\
\text { que a alguns emulsificantes apresentam características que permitem a união das duas fases } \\
\text { imiscíveis presentes na formulação. }\end{array}$ \\
\hline $\begin{array}{l}\text { Processo de separação e } \\
\text { purificação da } \alpha \text { - } \\
\text { lactoalbumina e } \beta \text { - } \\
\text { lactoglobulina por } \\
\text { combinação da } \\
\text { cromatografia de troca } \\
\text { iônica, sistemas aquosos } \\
\text { bifásicos e cromatografia } \\
\text { de exclusão molecular }\end{array}$ & $\begin{array}{l}\text { O processo foi desenvolvido para separação e purificação das proteínas a-lactoalbumina, a-la, } \\
\text { e b-lactoglobulina, b-lg, presentes no soro de leite, utilizando cromatografia de troca iônica, } \\
\text { sistemas aquosos bifásicos SAB e cromatografia de exclusão molecular. O setor técnico a que } \\
\text { pertence esta patente está classificado como necessidades humanas: produtos de laticínio; } \\
\text { produção dos mesmos; obtenção de composições de proteínas para produtos alimentícios; } \\
\text { preparação de peptídeos, p. ex. de proteínas em geral. Estas proteínas em forma purificada são } \\
\text { benéficas à saúde e permitem o desenvolvimento de alimentos especiais, como por exemplo, } \\
\text { alimentos para fenilcetonúricos. As características das proteínas do soro de leite aqui } \\
\text { mencionadas despertaram o interesse pela sua recuperação, purificação e comercialização, } \\
\text { ratificando a necessidade da implementação de um processo de recuperação de proteínas, } \\
\text { agregando valor a este sub-produto e diminuindo a poluição do meio ambiente. }\end{array}$ \\
\hline $\begin{array}{l}\text { Método de extração e } \\
\text { processamento de } \\
\text { produtos à base de polpa } \\
\text { integral de bacaba }\end{array}$ & $\begin{array}{l}\text { No método de extração e processamento de produtos à base de polpa integral de bacaba, } \\
\text { desenvolvido para aplicação em fins industriais, é preciso que os frutos passem por seleção, } \\
\text { lavagem, maceração em água e despolpamento a fim de obtenção de produto com características } \\
\text { integrais. Posteriormente a polpa pode ser usada para extração da parte lipídica e o restante de } \\
\text { polpa e cascas utilizado para desenvolvimento de novos produtos como geleias. A presente } \\
\text { invenção é caracterizada pelo aproveitamento integral da parte comestível do fruto da bacaba e } \\
\text { desenvolvimento de produtos à base de polpa integral de bacaba com finalidade de } \\
\text { aproveitamento na alimentação humana. O processo de obtenção da polpa e dos produtos finais } \\
\text { de caracterizam por serem inéditos quanto a proposta de aproveitamento e modo de obtenção. } \\
\text { Por meio desse método, a polpa integral de bacaba possui alta versatilidade podendo ser usada } \\
\text { no desenvolvimento de grande número de produtos. }\end{array}$ \\
\hline $\begin{array}{l}\text { Processo de adição de } \\
\text { ácido graxo como } \\
\text { matéria prima na massa } \\
\text { de cerâmica vermelha }\end{array}$ & $\begin{array}{l}\text { As empresas de cerâmica vermelha utilizam matérias-primas argilosas naturais no processo de } \\
\text { fabricação de seus produtos, as quais estão sujeitas a larga variabilidade de suas propriedades. } \\
\text { As propriedades mecânicas dos produtos de cerâmica vermelha são dependentes da composição } \\
\text { das argilas e das condições de processamento que são empregados. A temperatura de queima é }\end{array}$ \\
\hline
\end{tabular}




\begin{tabular}{|c|c|}
\hline & $\begin{array}{l}\text { um parâmetro de processamento que tem grande influência nas propriedades tecnológicas, um } \\
\text { conjunto bastante complexo de reações físico-químicas, dependentes da temperatura de queima, } \\
\text { e se processa no interior da massa cerâmica. Essas reações promovem a formação de novas } \\
\text { fases cerâmicas, que são determinantes para as propriedades físico-mecânicas no produto final. } \\
\text { A indústria cerâmica tem uma capacidade de absorver resíduos em até } 5 \% \text { na sua massa. Este } \\
\text { trabalho mostra a influência da adição do ácido graxo um resíduo da glicerina na massa } \\
\text { cerâmica. Durante os ensaios realizados em laboratórios, ficou comprovada o melhoramento } \\
\text { das argilas e uma massa cerâmica com propriedades especificas. Os percentuais que podem ser } \\
\text { adicionados em peso na massa cerâmica foram formulações: } 0,5 \%, 1 \% \text { e } 1,5 \% \text { de ácido graxo. } \\
\text { A temperatura de queima das peças foi controlada entre } 700 \text { a } 1000^{\circ} \mathrm{C} \text {, de acordo a amostra que } \\
\text { foi sinterizada. As porcentagens de ácidos graxos adicionados reduzem a absorção da água na } \\
\text { massa cerâmica, também o tempo de queima da cerâmica e a quantidade de combustível } \\
\text { necessário no processo de produção. A queima do ácido graxo junto com a argila no processo } \\
\text { de sinterização não emite gases tóxicos ou poluentes, atendendo as orientações preconizadas } \\
\text { nas normas da ABNT } 10.004,10.005 \text { e } 10.006 \text {. As amostras foram caracterizadas químicas e } \\
\text { mecanicamente de acordo com as normas: Retração Linear ASTM } 210 / 95 \text {, Porosidade Aparente } \\
\text { ASTMC } 373 / 94-88 \text {, Resistência Mecânica ASTMC } 133 / 97 \text {. }\end{array}$ \\
\hline $\begin{array}{l}\text { Biorreator com cesto } \\
\text { poroso para uso em } \\
\text { reações com células e } \\
\text { enzimas imobilizadas }\end{array}$ & $\begin{array}{l}\text { A presente invenção consiste em um biorreator verticalmente alongado contendo em seu interior } \\
\text { um cesto poroso para utilização em reações com enzimas imobilizadas. O aparelho consiste em } \\
\text { um vaso de reação confeccionado em vidro verticalmente alongado possuindo uma (1) entrada } \\
\text { para reagente líquido e uma (1) saída de produto; contendo um cesto completamente submerso } \\
\text { no meio reacional. Partículas biocatalisadoras imobilizadas compreendendo enzimas são } \\
\text { colocadas dentro do recipiente poroso, de tal modo que o reagente líquido entre em contato com } \\
\text { o biocatalisador tanto em direção radial como axial. O ponto de alimentação do biorreator pode } \\
\text { ficar localizado em qualquer ponto ao longo das dimensões do mesmo, mas de preferência, a } \\
\text { uma parte superior ou na extremidade inferior do vaso. Tal invenção tem a vantagem de permitir } \\
\text { um maior contato entre os reagentes e o biocatalisador, que por sua vez aumenta a velocidade } \\
\text { de reação e a eficiência da reação biocatalítica. Outra vantagem é que o biocatalisador pode ser } \\
\text { separado a partir da mistura de reação, simplesmente por drenagem do líquido circulante. }\end{array}$ \\
\hline $\begin{array}{l}\text { Gabarito portátil para } \\
\text { construção de } \\
\text { pingadeiras }\end{array}$ & $\begin{array}{l}\text { A presente invenção diz respeito a um molde constituído em duas peças e mais uma cantoneira } \\
\text { as quais deverão ser encaixadas lateralmente na parte superior do muro (3), sendo uma de cada } \\
\text { lado, em que ambas serão presas por meio de um aparato fixador (4) e (5) que pode ser um } \\
\text { "sargento" (5). Cada peça é dotada de reentrância em forma de "concha (2)," idealizada de } \\
\text { forma a receber a argamassa (7) fornecendo um formato apropriado para receber a água da } \\
\text { chuva (8), com a finalidade de evitar o escorrimento da água em muros e fachadas. O campo de } \\
\text { aplicaçãa técnica deste produto é de materiais para construção civil. }\end{array}$ \\
\hline $\begin{array}{l}\text { Uso do gel de quitosana } \\
\text { como coagulante e } \\
\text { floculante no tratamento } \\
\text { de águas e efluentes }\end{array}$ & $\begin{array}{l}\text { Refere-se ao uso de gel contendo quitosana que pode agir como coagulante e floculante no } \\
\text { tratamento de águas e efluentes. O setor técnico a que se refere esta patente é o de tratamento } \\
\text { de água, águas residuais, de esgotos ou de lamas e lodos. O gel de quitosana possui a vantagem } \\
\text { de ser um produto de composição inteiramente orgânica, biodegradável e atóxico para o meio } \\
\text { ambiente. Pode substituir a forma usual de tratamento, realizada com compostos químicos, } \\
\text { substituindo os produtos convencionais sulfato de alumínio, sulfato de ferro e outros similares } \\
\text { de elevada toxicidade. A utilização do gel de quitosana demonstrou em testes realizados em } \\
\text { laboratório, eficiência superior aos dos coagulantes e floculantes a base de sais de alumínio e } \\
\text { ferro. Além do baixo índice de toxicidade e formação de lodo. }\end{array}$ \\
\hline $\begin{array}{l}\text { Separação de proteínas } \\
\text { do soro de leite bovino } \\
\text { com aplicação do babaçu }\end{array}$ & $\begin{array}{l}\text { A presente invenção refere-se ao processo separação das proteínas do soro de leite bovino com } \\
\text { a aplicação do carvão ativo do coco Babaçu na indústria de alimentícia, farmacêutica e ou } \\
\text { nutracêutica, No processo de separação foi utilizado Babaçu, precisamente, endocarpo e } \\
\text { mesocarpo de Babaçu como material adsorvente na separação da proteína do soro de leite } \\
\text { bovino, a albumina de soro bovino (BSA). O processo de separação da proteína do soro de leite } \\
\text { foi realizado utilizando técnicas de centrifugação e adsorção, bem como tratamento } \\
\text { termoquímico preliminar adequado. Resultados mostraram que o Babaçu, precisamente o } \\
\text { endocarpo e mesocarpo de babaçu apresentou boa capacidade máxima de adsorção (qm) e } \\
\text { consequentemente boa eficiência. }\end{array}$ \\
\hline $\begin{array}{l}\text { Maionese com polpa de } \\
\text { açaí e o seu respectivo } \\
\text { método de } \\
\text { processamento }\end{array}$ & $\begin{array}{l}\text { A maionese de açaí é uma emulsão de óleo/água adicionada de polpa de açaí, além de outros } \\
\text { componentes aqui descritos, apresenta aplicação no setor técnico da indústria de alimentos. } \\
\text { Obtida por meio dos seguintes componentes: óleos/azeites vegetais, ovo em pó, polpa de açaí, } \\
\text { água, ácido cítrico, ácido lático, sorbato de potássio, vinagre branco, sal refinado, açúcar cristal, } \\
\text { edulcorantes e goma xantana. O processo de fabricação é de fácil execução de acordo com a } \\
\text { mistura dos componentes e possui aporte calórico menor que a maionese tradicional. O seu } \\
\text { consumo reduz a ingestão de ácidos graxos saturados e aumenta o consumo de ácidos graxos }\end{array}$ \\
\hline
\end{tabular}




\begin{tabular}{|c|c|}
\hline & $\begin{array}{l}\text { poli-insaturados e monoinsaturados além de ácidos graxos essenciais, como o ômega } 3 \text { e ômega } \\
6 \text {, além das antocianinas e antocianidinas presentes naturalmente na polpa do açaí. }\end{array}$ \\
\hline $\begin{array}{l}\text { Bebida láctea à base de } \\
\text { extrato hidrossolúvel de } \\
\text { amêndoa de babaçu e seu } \\
\text { processo de obtenção } \\
\text { com cultura probiótica }\end{array}$ & $\begin{array}{l}\text { O presente invento refere-se ao processo de fabricação de uma bebida láctea fermentada e este } \\
\text { produto contendo culturas probióticas incorporados a uma matriz constituída de leite e/ou seus } \\
\text { derivados e amêndoa de babaçu (Orbignya speciosa). A presente invenção pertence ao campo } \\
\text { da Engenharia de Alimentos. Especificamente refere-se a um processo de produção de produto } \\
\text { alimentício fermentado a base de amêndoa de babaçu com cultura probiótica e está relacionado } \\
\text { aos usos da bebida láctea probiótica como alimento funcional indicado a doenças crônicas } \\
\text { intestinais, dietas de emagrecimento, síndrome metabólica, úlcera peptídica, diabetes, doenças } \\
\text { auto-imunes, diminuição do colesterol, prevenção de câncer entre outros. }\end{array}$ \\
\hline $\begin{array}{l}\text { Processo para produção } \\
\text { de monossacarídeos } \\
\text { fermentescíveis a partir } \\
\text { de quitina e/ou quitosana } \\
\text { por hidrólise química } \\
\text { e/ou hidrólise enzimática } \\
\text { e seus usos }\end{array}$ & $\begin{array}{l}\text { A presente invenção apresenta um processo para obtenção de monossacarídeos em solução } \\
\text { aquosa ácida a partir de quitina ou quitosana por meio de hidrólise química e ou enzimática. } \\
\text { Este processo permite a obtenção de solução de açúcares fermentescíveis ou não } \\
\text { fermentescíveis utilizando reagentes de baixo custo e de fácil aquisição, os quais possuem } \\
\text { importância industrial. O setor técnico a que se refere esta invenção visa prover, por meio de } \\
\text { um novo processo de produção, a indústria de alimentação e/ou indústria química, por meio de } \\
\text { um método alternativo de fabricação de monossacarídeos mais simples e. portanto mais viável } \\
\text { do ponto de vista técnico-econômico. }\end{array}$ \\
\hline $\begin{array}{l}\text { Uso do óleo essencial de } \\
\text { Morinda citrifolia (Noni) } \\
\text { em formulação com fins } \\
\text { inseticida e repelente }\end{array}$ & $\begin{array}{l}\text { a presente invenção trata-se de uma formulação à base de óleo essencial dos frutos maduros de } \\
\text { Morinda citrifolia (Noni) com fins ovicida, larvicida, pupicida, adulticida, inseticida e repelente } \\
\text { contra todos os estádios de Aedes aegypti. Estas formulações podem ser preparadas na forma } \\
\text { de aerossol, soluções líquidas, pastas, géis, cremes, suspensões, pomadas, impregnados em } \\
\text { suportes físicos para liberação eletrônica e através de dispositivos de queima e liberação por } \\
\text { calor e podem estar associadas ou não a outros compostos inseticidas naturais e/ou sintéticos e } \\
\text { a adjuvantes e veículos. }\end{array}$ \\
\hline $\begin{array}{l}\text { ra } \\
\text { pa UFMG } \\
\text { ão de } \\
\text { tico }\end{array}$ & $\begin{array}{l}\text { descreve a aplicação da levedura em sorvete. A tecnologia proposta se presta à adição da } \\
\text { levedura em sorvetes na forma livre em números controlados de células, gerando benefícios } \\
\text { para a saúde humana e promovendo uma nova categoria de alimento probiótico, tratando-se } \\
\text { dessa forma de um invento referente ao setor técnico agro-industrial. Essa levedura resiste ao } \\
\text { armazenamento em temperaturas críticas e condições de produção industrial de sorvetes sem } \\
\text { afetar as características físicas, químicas e sensoriais do produto. Este micro-organismo pode } \\
\text { ser aplicado diretamente no alimento sem passar pela fermentação do leite, etapa geralmente } \\
\text { aplicada quando utilizadas bactérias probióticas. }\end{array}$ \\
\hline $\begin{array}{l}\text { Espuma vítrea com } \\
\text { adição de vidro } \\
\text { sodocálcico, cinza da } \\
\text { casca de arroz e } \\
\text { carbonato de cálcio de } \\
\text { grau P.A }\end{array}$ & $\begin{array}{l}\text { Comprovou-se a influência da adição da cinza da casca de arroz no vidro sodocálcio com adição } \\
\text { de carbonato de cálcio para obtenção de uma espuma cerâmica com excelentes propriedades } \\
\text { térmicas e acústicas. O percentual adicionado de cinza da casca de arroz em relação ao peso do } \\
\text { vidro sodocálcico pode variar de } 5 \text { até } 30 \% \text {. O carbonato de cálcio também terá sua massa em } \\
\text { relação a massa do vidro sodocálcico com percentual de adição entre } 10 \% \text {. A temperatura de } \\
\text { sinterização das peças foi controlada entre } 650 \text { a } 1100^{\circ} \mathrm{C} \text {, de acordo a amostra que foi } \\
\text { sinterizada. A formulação ainda recebe adição de } 5 \% \text { de água e } 5 \% \text { de PVA (Álcool } \\
\text { polivinílico). Para garantir a eficiência uma rampa de queima de } 100 /{ }^{\circ} \mathrm{C} / \mathrm{h} \text { e feita e uma rampa } \\
\text { de resfriamento e necessária com } 100^{\circ} \mathrm{C} / \mathrm{min} \text {. }\end{array}$ \\
\hline $\begin{array}{l}\text { a de arroz, } \\
\text { cico e } \\
\text { cálcio }\end{array}$ & $\begin{array}{l}\text { Descreve um produto e método para produção de agregado. A adição controlada em peso de } \\
\text { vidro sodocálcico, cinza da casca de arroz (CCA) e carbonato de cálcio (CaCO3) dão origem a } \\
\text { um agregado leve, rígido, quimicamente inerte e não tóxica. Esta formulação produz um produto } \\
\text { ambientalmente correto. As formulações dos materiais e o processo de produção desenvolvido } \\
\text { resultam em um agregado leve, rígido, com alta resistência a compressão uniaxial com baixa } \\
\text { absorção de água, quimicamente inerte e não tóxica que reduz o peso próprio de estruturas de } \\
\text { concreto como vigas, pilares e lajes. O agregado produzido pode ser utilizado em substituição } \\
\text { parcial ao agregado natural extraído no meio ambiente. As propriedades tecnológicas do } \\
\text { material desenvolvido são capazes de reduzir o custo com a redução do peso próprio das } \\
\text { estruturas em obras de construção civil. }\end{array}$ \\
\hline $\begin{array}{l}\text { Uso de isolados de } \\
\text { Trichoderma tolerantes } \\
\text { as radiações solares UV- } \\
\text { B e UV-A em formulação } \\
\text { de biofungicida }\end{array}$ & $\begin{array}{l}\text { Descreve isolados do fungo Trichoderma sp. tolerantes as radiações solares UV-B e UV-A } \\
\text { por uma e duas horas, uma formulação à base de quatro isolados do fungo Trichoderma (UFTG } \\
08 \text {, UFTG 09, UFTG 13, UFTG 48) e seus metabólitos com fins biofungicidas, controlando } \\
\text { cinco fitopatógenos (Sclerotinia sclerotiorum, Rhizoctonia solani, Colletotrichum spp., } \\
\text { Fusarium spp. e Macrophomina spp.), compatíveis com cinco fungicidas químicos (Fluazinam, } \\
\text { Fluopyram, Azoxistrobina, Difenoconazole e Captana), produzidos em arroz parboilizado e }\end{array}$ \\
\hline
\end{tabular}




\begin{tabular}{|c|c|}
\hline & $\begin{array}{l}\text { farelo de arroz e tolerantes a uma e duas horas de exposição as radiações solares UV-B e UV- } \\
\text { A em campo. }\end{array}$ \\
\hline $\begin{array}{l}\text { Desmoldante para a } \\
\text { construção civil baseado } \\
\text { em oligômeros do glicerol } \\
\text { e seus derivados }\end{array}$ & $\begin{array}{l}\text { A presente invenção relata o uso de oligômeros de glicerol e seus derivados de oxidação e } \\
\text { desidratação como componentes para uma formulação de desmoldante para aplicação na } \\
\text { indústria da construção civil. O desmoldante pode ser usado na fabricação de artefatos } \\
\text { cimentícios pré-moldados e apresenta algumas características importantes, tais como: (i) } \\
\text { capacidade em aderir a formas, principalmente de madeira; (ii) capacidade de reter água ou } \\
\text { absorver da forma, mantendo o artefato cimentício úmido por mais tempo, favorecendo a cura } \\
\text { do cimento; (iii) capacidade de formar sobre a forma, um filme flexível e resistente a vibrações } \\
\text { e a ação abrasiva do concreto úmido, ao ser adicionado; (iv) facilidade de ser removido da forma } \\
\text { e principalmente do artefato cimentício, já que é um produto solúvel em água; (v) facilidade de } \\
\text { se combinar com aditivos diversos (polares ou apolares e poder ser utilizado como aditivo } \\
\text { retardador de pega do cimento; (vi) ser derivado de um subproduto da produção de um } \\
\text { biocombustível e (vii) ser biodegradável. }\end{array}$ \\
\hline $\begin{array}{l}\text { Geossintético natural } \\
\text { com matriz de fibra do } \\
\text { epicarpo de coco babaçu }\end{array}$ & $\begin{array}{l}\text { Patente de Modelo de Utilidade para a produção de mantas sintéticas (ou biomantas) destinadas } \\
\text { ao controle de processo erosivos superficiais e revegetação, em taludes ou canais, situação bem } \\
\text { recorrente em intervenções promovidas pelo setor da construção civil. A proposta traz uma } \\
\text { biomanta composta por uma matriz orgânica proveniente das fibras do epicarpo do coco babaçu, } \\
\text { as quais são confinadas entre duas redes sintéticas (geralmente polímeros termoplásticos de } \\
\text { preferência fotodegradáveis e/ou biodegradáveis) que confinam a matriz e garantem uma maior } \\
\text { rigidez e trabalhabilidade durante a aplicação da biomanta. A adoção de fibras do coco babaçu } \\
\text { como matriz em mantas sintéticas (ou biomantas) apresenta comportamento semelhante as já } \\
\text { existentes no mercado, além de garantir benefícios na redução dos custos de transporte e no } \\
\text { incentivo a instalação de novas plantas industriais, em regiões do país onde este vegetal é } \\
\text { endêmico. }\end{array}$ \\
\hline Kit Saco d & $\begin{array}{l}\text { Trata-se de um pedido de depósito de patente de Modelo de Utilidade adaptado para qualquer } \\
\text { tipo de saco de lixo e lixeira, sendo que ambos se apresentam com suas peculiaridades. O Setor } \\
\text { Técnico ou tecnológico a que pertence o presente pedido de patente é o de coleta ou remoção } \\
\text { de lixo doméstico ou refugos ou receptáculos para refugos, com inserções removíveis ou } \\
\text { flexíveis, p. ex. sacos ou sacas, com dispositivos para facilitar o esvaziamento. O Modelo de } \\
\text { Utilidade é constituído de } 3 \text { partes que formam o conjunto: lixeira especial de acordo com } \\
\text { Figura1 e Figura 2, dispositivo de prendimento por suporte de gancho com eixo giratório (4) } \\
\text { em Figura 3, Figura } 4 \text { e Figura 5, sistema de sacos picotados unidos entre si conforme Figura } 9 \\
\text { e Figura 10. Todas estas partes se complementam, porém, nada impede que possam ser } \\
\text { utilizados separadamente caso seja critério do usuário, ou seja, os sacos de lixo (Figura 9, Figura } \\
\text { 10) ou lixeira especial (Figura } 1 \text { e Figura 2). A Figura } 1 \text { mostra o sistema completo acoplado na } \\
\text { lixeira com o saco de lixo para prender os sacos de lixos. A lixeira representada na Figura } 7 \text { e } \\
\text { Figura } 8 \text { tem sua aplicação vinculada ao sistema de sacos picotados unidos entre si conforme } \\
\text { Figura } 9 \text { e Figura } 10 \text {. }\end{array}$ \\
\hline $\begin{array}{l}\text { Uso de ácido propiônico } \\
\text { para o controle de } \\
\text { doenças pós-colheita em } \\
\text { vegetais }\end{array}$ & $\begin{array}{l}\text { Descreve o uso do ácido propiônico para criar uma atmosfera modificada que irá controlar o } \\
\text { crescimento de patógenos, responsáveis por doenças pós-colheita, propiciando uma vida de } \\
\text { prateleira maior para os vegetais e, dessa forma, esse invento se refere ao setor técnico agro- } \\
\text { industrial. A tecnologia proposta se presta ao controle da incidência e redução da severidade da } \\
\text { doença provocada por patógenos em vegetais, prolongando a vida de prateleira e minimiza as } \\
\text { perdas dos produtores e distribuidores durante o período de cultivo, transporte e } \\
\text { armazenamento, aumentando assim a oferta dos vegetais para o consumidor final. }\end{array}$ \\
\hline
\end{tabular}

Fonte: UFT, 2019.

\section{Análise das patentes depositadas}

Como toda patente depositada, há sempre o princípio de proteção quando há alguma ação inovativa no pedido de depósito, que é o mínimo exigido pelo Instituto Nacional de Propriedade Intelectual (INPI). Porém, apesar do princípio inovador, nem todas as patentes são passíveis de 
depósito anualmente e no fim do período não ter o retorno esperado. A partir disso, uma das principais exigências dos Núcleos de Inovação Tecnológicos NITS das Instituições de ensino superior (IES), é a de exigir alguma possibilidade de aplicação comercial.

Outro fator relevante é o de dimensionar o valor do Know How sobre o responsável pela criação do que será patenteado. $\mathrm{O}$ know how em muitos casos é medido pelo número de horas de pesquisa sobre a patente pata poder determinar o valor desse processo. É natural que nem todo valor desenvolvido sobre uma patente, necessariamente é um valor esperado, mas segue o princípio de Kotler (2014) do Valor Justo.

Ao observar detalhadamente cada patente depositada pela UFT, é perceptível que há algum processo para aplicação comercial, pois, não é característica da universidade investir em uma patente sem aplicação comercial, afinal, os valores de repasse do MEC para a educação superior tem diminuído nos últimos anos, e não é característica da universidade gastar seus recursos em patentes que, não possuem aplicação ou o princípio do retorno financeiro sobre o investimento.

\section{RESULTADOS}

Diante dos métodos discutidos neste artigo, analisando as patentes da tabela 3 , em análise a tabela 1 , o método que mais se assemelha ao princípio de um valor justo é o princípio de valoração por meios múltiplos, pois, como característica deste princípio, o efeito comparativo com outras tecnologias similares é o melhor, por poder determinar com características semelhantes o valor de mercado, alinhado ao fator inovador, auxiliará no levantamento de um valor justo.

Em análise a tabela 2, os melhores métodos para levantamento de valor sobre uma patente da universidade podem passar por mais de um método, neste caso podendo ser desenvolvido a partir do Cálculo do Valor de Intangibilidade (Stewart, 2001) sobre receita, Determinante de Intangibilidade (Gu e Lev, 2011) sobre receita, Fator tecnológico (Khoury, 1998) sobre receita, e Adicional de Coeficiente de Valoração Intelectual (Pulic, 2003) custo e receita. Mas para entender porque foram escolhidos esses fatores, discute-se os princípios e o que se assemelha com a situação da universidade:

a) As abordagens sobre mercado, visão mercadológicas, não podem ser determinadas pela Universidade até mesmo pelas dificuldades em obter o terno mercadológico, pela dificuldade em aplicar a Lei 13243/2016, principalmente por causa da falta de sintonia de interpretação por parte da procuradoria da UFT.

b) As abordagens sobre a receita permitem que se possa levar em consideração, além dos custos para teste, aperfeiçoamento, além dos valores pagos pela universidade para depósito e manutenção das patentes junto ao INPI;

c) Análise sobre o valor intelectual, sendo a UFT uma IES com finalidade de Pesquisa, Ensino e Extensão, determinando assim, o poder de concentração de capital intelectual, além da proximidade com a sociedade e o Estado;

d) Os custos sobre uma patente, também, segundo a análise de determinação de preço de venda que leva em consideração os custos e despesas para uma patente, e a partir disso, uma análise do custo do produto ou serviço oriundo da patente, com aplicação comercial.

Os fatores determinados nesta discussão, são uma realidade desta IES, e podem servir de princípio para que os métodos de valoração por receita sejam, na visão destes pesquisadores, os melhores métodos para determinação de valor de uma patente.

Tomando por base uma das patentes descritas neste artigo, será elaborado um princípio de cálculo sobre uma patente presente no portfólio de patentes da 
UFT. A patente de modelo de Utilidade de Desmoldante para a construção civil baseado em oligômeros do glicerol e seus derivados. Esta patente centra-se em: Usar oligômeros de glicerol e seus derivados de oxidação e desidratação como componentes para uma formulação de desmoldante para aplicação na indústria da construção civil.

Utilizando o método de Adicional de Coeficiente de Valoração Intelectual (Pulic, 2003) sobre custo e receita, determina-se alguns fatores para valorar esta patente. Obs.: Não será determinado um valor, mas sim pressupostos que podem aumentar o valor percebido desta patente. Fatores:

a) A patente é um modelo de utilidade para aplicação na construção civil. A construção civil representa 6,2\% do PIB de acordo com dados da CBIC, com faturamento de aproximadamente $\mathrm{R} \$ 280$ bilhões de reais;

b) O Brasil possui 126.319 empresas ativas em 2017;

c) O potencial da patente é determinado pela produtividade que gerará a construção civil, uma vez que a patente não se restringe a uma única atividade da construção civil.

d) O desmoldante pode ser usado na fabricação de artefatos cimentícios pré-moldados e apresenta algumas características importantes, tais como: (i) capacidade em aderir a formas, principalmente de madeira; (ii) capacidade de reter água ou absorver da forma, mantendo o artefato cimentício úmido por mais tempo, favorecendo a cura do cimento; (iii) capacidade de formar sobre a forma, um filme flexível e resistente a vibrações e a ação abrasiva do concreto úmido, ao ser adicionado; (iv) facilidade de ser removido da forma e principalmente do artefato cimentício, já que é um produto solúvel em água; (v) facilidade de se combinar com aditivos diversos (polares ou apolares e poder ser utilizado como aditivo retardador de pega do cimento; (vi) ser derivado de um subproduto da produção de um biocombustível e (vii) ser biodegradável.

Sob estas análises, e principalmente pelo fato do artefato ser biodegradável, o que já, aumenta a responsabilidade ambiental sobre a patente, se pudesse determinar um valor desta patente, analisando apenas o pressuposto de venda em sua totalidade para uma indústria, já poderia superar tranquilamente a casa dos milhões de reais, principalmente, que o Brasil não é o principal país e construção civil, e a patente não ser unicamente restrita ao país, podendo ser revendido ou utilizado por empresas de outras nações.

\section{CONSIDERAÇÕES FINAIS}

Um fator é verdadeiro, não é fácil determinar a valoração de qualquer produto, serviço, princípio ou processo no mercado, principalmente, pela escassez de especialistas no mercado brasileiro em apoio às universidades, sendo um condicionante, além é claro, do excesso de burocracia dos órgãos federais sobre as atividades das universidades no Brasil.

Alinhado a estes fatores, vem o de proteger os pesquisadores e as instituições sobre tudo que é desenvolvido, e obter retorno financeiro sobre a evolução dos princípios norteadores sobre a educação superior são chave para que as universidades tenham o justo retorno sobre o que é desenvolvido em seu ambiente.

As teorias sobre valoração, embora discutidos alguns autores, não se restringe a esses, mas a vários autores, bem como existem especialistas em valoração, que em momentos acertam, em momentos erram, mas que em nada diminui a importância em entender e desenvolver valores que sejam justos tanto para desenvolvedores como para utilizadores. 
Todos os autores declararam não haver qualquer potencial conflito de interesses referente a este artigo.

\section{REFERÊNCIAS}

ADRIANO, Eunice. ANTUNES, Maria Thereza Pompa. Proposta para mensuração de patentes. Rio de Janeiro: Revista de administração contemporânea (RAC), v. 21, n. 1, 2017.

ANDRIESSEN, D. Making sense of intellectual capital: design a method for the valuation of intangibles. Oxford, USA: Elsevier ButterwordHeinemann, 2004.

BRAGA, H. R. e ALMEIDA, M. C. Mudanças contábeis na lei societária: Lei ${ }^{\circ} 11.638$, de 2812-2007. São Paulo: Atlas, 2008.

BIENIAS, Emma. CORNELIUS, Candice. Financing alternatives for companies: using intellectual property as colatteral. Disponível em: $<$

fr/insights/article/financing-alternativescompanies-using-intellectual-propertycollateral> acesso em 15/14/2019.

CBIC - Dados estatísticos econômicos sobre a construção civil no Brasil em 2017. Disponível em: $<$

http://www.cbicdados.com.br/menu/estudosespecificos-da-construcao-civil/pesquisa-anualda-industria-da-construcao-paicibge $>$ acesso em 15 de junho de 2019.

CHIU, Yu Jing. CHEN, Yuh When. Using AHP in patent Valuation. Elsevier, 2007. Pag. 10541062.
DE CARVALHO, R. L.; DA SILVA, T. A.; GONÇALVES, F. B. Uma análise da importância das patentes relacionadas ao software. Revista Observatório, v. 5, n. 5, p. 567-585, 1 ago. 2019.

DIXIT, A. K. PINDYCK, R. S. The options approach to capital investment (International Library of Critical Writings in Economics Series 163). Cheltenham, UK: Edward Elgar Publishing, 2003.

GU, F., LEV, B. Overpriced Shares, Ill-Advised Acquisitions, and Goodwill Impairment. The Accounting Review, 2011.

GUIMARÃES, Yuri Basile Tukoff. Valoração de patentes nas universidades públicas do Estado de São Paulo. Uninove: São Paulo, 2013.

INPI, Instituto Nacional de Propriedade Intelectual (2018). Manual para o depositante de Patentes. Disponível em: < www.inpi.gov.br/menuservicos/patente/.../manual-para-o-depositantede-patentes.pdf $>$ acesso em 26/04/2019. . Indicadores de propriedade industrial. Rio de Janeiro: INPI, 2017.

KNIGHT, Frank H. Risk, uncertainty and profit. Reprints of economics classic, New York, 1964.

KHOURY, S. Valuing intellectual properties. New York: John Wiley \& Sons, Inc, 1998. 
KOTLER, Phillip. KELLER, Kavin Lane. Administração de Marketing. São Paulo: Elsevier, 2014.

LEE, T. Income and value measurement. London: International Thomson Business Press, 1996.

LIMA, Gerlando Augusto Sampaio Franco. A relação do acompanhamento dos analistas com características de valuation das empresas brasileiras. São Paulo: Usp, 2013.

NUNES, S. G.; PORTO JUNIOR, F. G. R.; MORAES, N. R. DE. Conhecimento e organização: indicativos pós-Bolonha de uma sociedade em construção. Revista Observatório , v. 3, n. 6 , p. 338-353, 1 out. 2017.

\section{OCDE (Organização Para Cooperação e} Desenvolvimento Econômico), Capítulo 8 "Indicators of Patent Value" In: OCDE, "Patent Statistics Manual”. 2009.

PADOVEZE, Clóvis Luiz. O papel da contabilidade gerencial no processo empresarial de criação de valor. Caderno de Estudos n. 21: São Paulo, 1999.

PAIVA, Pedro Henrique de Abreu. SHIKI, Simone de Faria Narciso. Método de Valoração de Patentes para o NIT: UFSJ. Revista Conexões, v. 11, n. 3, P. 84-92, Novembro/2017.

PITA, Alberto Coelho Análise do valor e valoração de patentes: método e aplicação no setor petroquímico brasileiro / A.C. Pita. -- São Paulo, 2010.

PITKETHLY, R.H. The valuation of patents: A review of patent valuation methods with consideration of option based methods and the potential for further research. Available at: www.oiprc.ox.ac.uk/EJWP0599.html, 1997.

PULIC, A. Intellectual capital - does it create or destroy value? Measuring Business Excellence, v. 8., 2004.

PORTO JUNIOR, F. G. R.; MORAES, N. R. DE. Formando pesquisadores pós-bolonha em Portugal: relações entre a formação de graduação e o campo da pesquisa/investigação. Revista Observatório, v. 3, n. 6, p. 202-228, 1 out. 2017.

REILLY, R. F. ROBERT, P. S. Valuing intangible assets. New York: McGraw-Hill, 1999. SILVA, B. D.; SARTORI, A. S.; MARTINI, R. G. As tecnologias de informação e comunicação como agentes de integração do currículo com a glocalidade. Revista Observatório, v. 3, n. 4, p. 387-406, 1 jul. 2017.

SOUSA, K. A.; LUCAS , M. R.; SOUZA, D. O. DE S.; COSTA, B. B. A produção da banana e seus impactos socioeconômicos no desenvolvimento da microrregião de araguaínaTO. Revista Observatório, v. 5, n. 5, p. 314-350, 1 ago. 2019.

SOUSA, D. L. DA L.; SOUSA, K. A.; SANTOS JÚNIOR, D. P. DOS. Gestão da inovação em 
serviços públicos: um estudo de caso em um órgão executivo de trânsito, a partir da análise de indicadores. Revista Observatório, v. 5, n. 5, p. 283-313, 1 ago. 2019.

STANDFIELD, K. Time capital and intangible accounting: the approaches to intellectual capital. In Y. Malhotra (Ed.), Knowledge management and business model innovation (pp. 316-324). Hershey. PA: Idea Group Publishing, 2001.

SMITH, G. V. PARR, L. R. Valuation of intellectual property and intangible assets. New York, NY: John Wiley \& Sons,1994.

STEWART, T. A. The wealth of knowledge: intellectual capital and the twenty-first century organization. New York: Doubleday, 2001.
STEWART, G. B. EVA: Fact and fantasy. Journal of Applied Corporate Finance: New York, 1994.

WARTHBURG, Iwan Von. TEICHERT, Thorsten. Valoração de patentes e licenças de uma perspectiva de estratégias de negócios Estendendo considerações de valoração usando a nanotecnologia. Revista Elsevier, vl 30 ed. 2. Hamburgo, ALE, 2008.

WIEDERHOLD, G. TESSLER, S. GUPTA, A. SMITH, D. B. The Valuation of TechnologyBased Intellectual Property In Offshoring Decisions. Communications of the Association for Information Systems, 2009. 